\title{
Application of Electron Backscatter Diffraction (EBSD) for Crystallographic Characterization of Aluminum-Doped Zinc Oxide Sputtered Films
}

\author{
C.B. Garcia*, E. Ariza***** and C.J. Tavares* \\ *Centro de Física, Universidade do Minho, Guimarães, Portugal \\ **SEMAT/UM, Universidade do Minho, Guimarães, Portugal \\ ***CT2M, Universidade do Minho, Guimarães, Portugal
}

Zinc Oxide is a wide band-gap compound semiconductor [1] that has been used in optoelectronic and photovoltaic applications due to its good electrical and optical properties. Aluminium has been an efficient $n$ type dopant for $\mathrm{ZnO}$ to produce low resistivity films and high transparency to visible light [2]. In addition, the improvement of these properties also depends on the morphology, crystalline structure and deposition parameters. In this work, $\mathrm{ZnO}: \mathrm{Al}$ films were produced by d.c. pulsed magnetron sputtering deposition from a $\mathrm{ZnO}$ ceramic target $\left(2.0 \mathrm{wt} \% \mathrm{Al}_{2} \mathrm{O}_{3}\right)$ on glass substrates, at a temperature of $250{ }^{\circ} \mathrm{C}$.

The crystallographic orientation of aluminum doped zinc oxide ( $\mathrm{ZnO}: \mathrm{Al})$ thin films has been studied by Electron Backscatter Diffraction (EBSD) technique. EBSD coupled with Scanning Electron Microscopy (SEM) is a powerful tool for the microstructural and crystallographic characterization of a wide range of materials [3-4].

The investigation by EBSD technique of such films presents some challenges since this analysis requires a flat and smooth surface [5]. This is a necessary condition to avoid any shadow effects during the experiments performed with high tilting conditions $\left(70^{\circ}\right)$. This is also essential to ensure a good control of the three dimensional projection of the crystalline axes on the geometrical references related to the sample [6].

Crystalline texture is described by the inverse pole figure (IPF) maps (Figure 1). Through EBSD analysis it was observed that the external surface of the film presents a strong texture on the basal plane orientation (grains highlighted in red colour). Furthermore it was possible to verify that the grain size strongly depends on the deposition time (Figure 1 (a) and (b)). The electrical and optical film properties improve with increasing of the grain size, which can be mainly, attributed to the decrease in scattering grain boundaries [6] which leads to an increasing in carrier mobility (Figure 2).

\section{References}

1. Ellmer K et al., In: Springer Series in Materials Science 104, Springer, Berlin, Germany, 2008

2. Lu JG et al., J. Appl. Phys. 101:083705,2007

3. Schwartz AJ et al., Electron Backscatter Diffraction in Materials Science. In: Kluver Academic/Plenum, New York, 2000.

4. Schwartz A et al., Electron Backscatter Diffraction in Materials Science. In: Springer, Second ed., 2009

5. Randle V., Mater. Charact. 60:913-922,2009

6. Garcia CB et al., Appl. Surf. Sci. 259:590-595,2012 

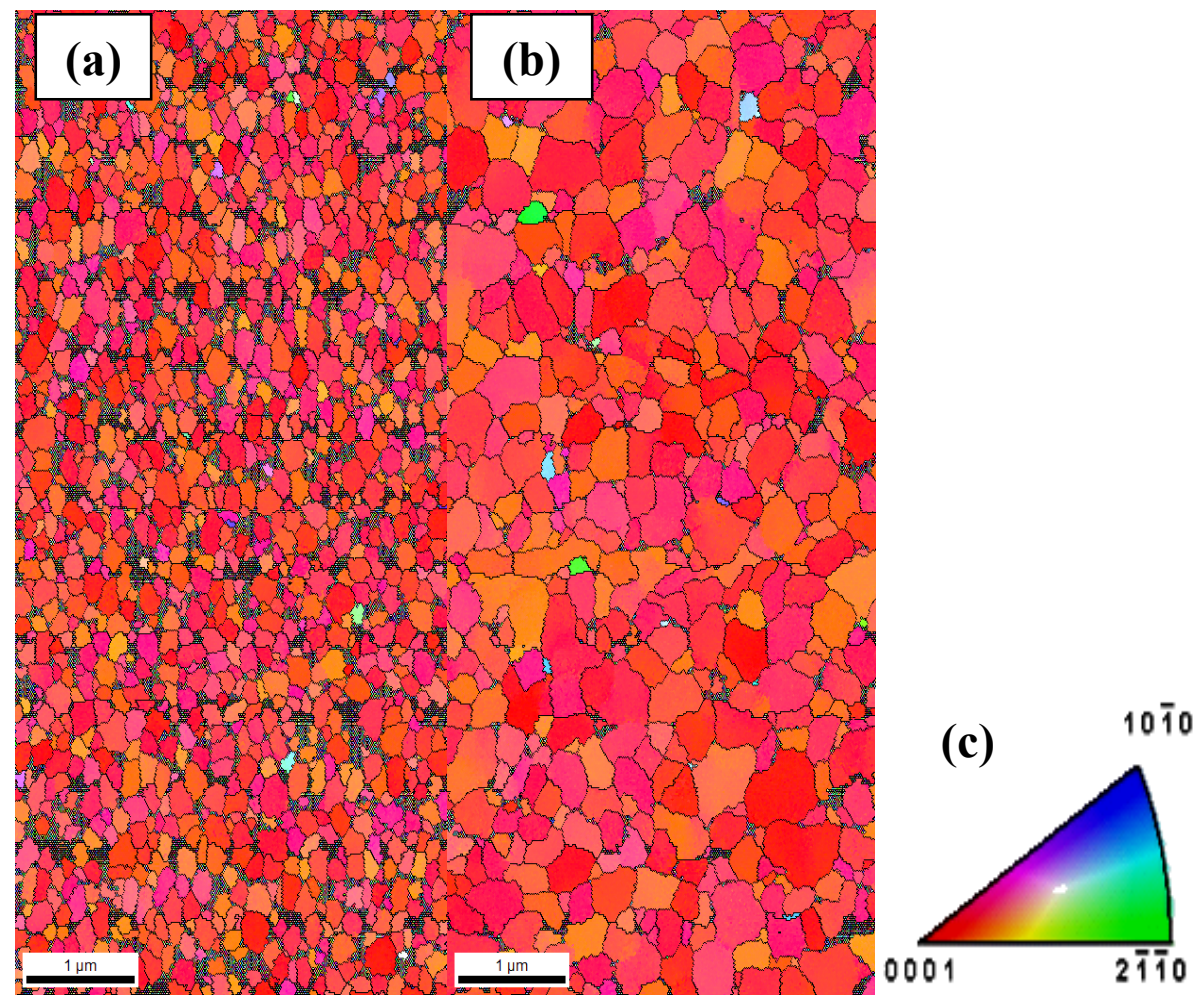

Figure 1. EBSD inverse pole figure (IPF) maps showing the [0001] preferred grain orientation relatively to the sample normal direction: (a) deposition time of 15 minutes; (b) deposition time of 60 minutes; (c) Stereographic triangle.

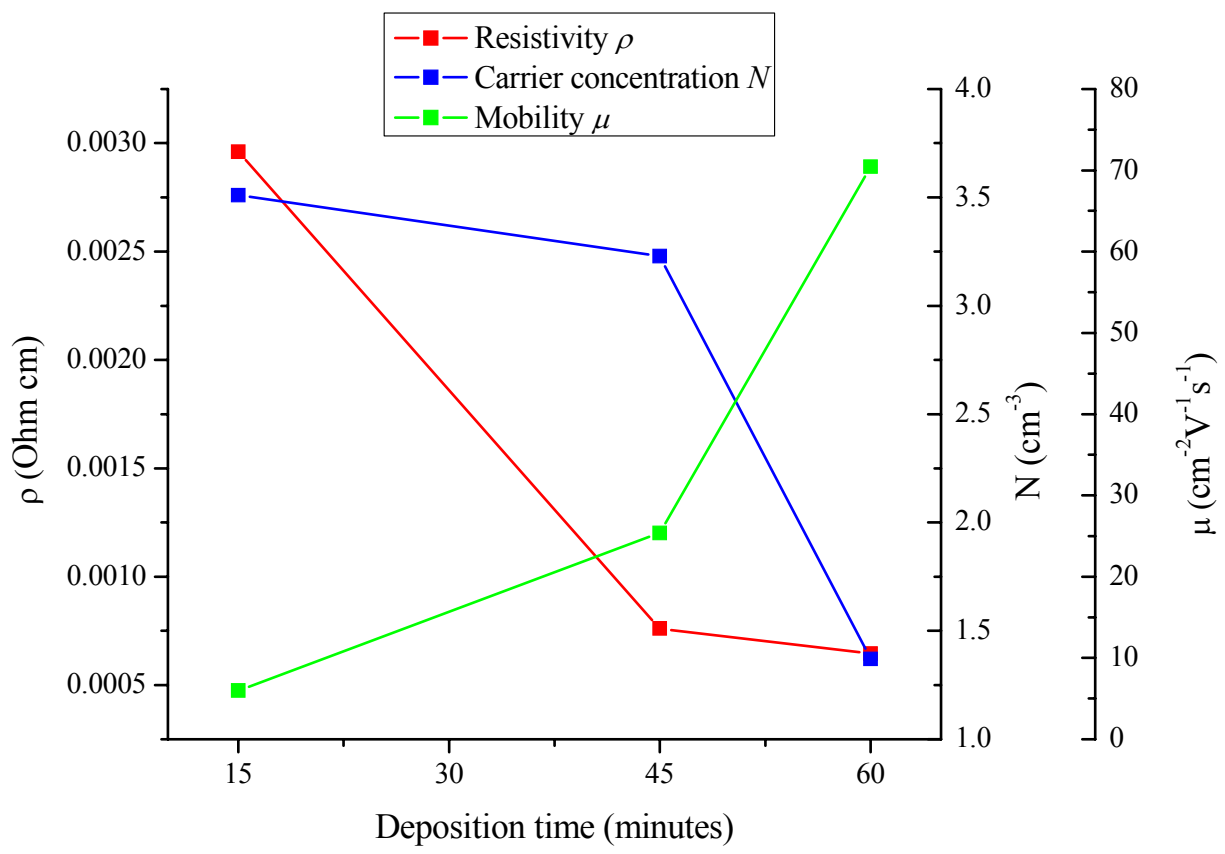

Figure 2. Resistivity $\rho$, carrier concentration $N$ and mobility $\mu$, for $\mathrm{ZnO}$ :Al thin films as a function of deposition time (15, 45 and 60 minutes).

The authors kindly acknowledge the financial support from the Portuguese Foundation for Science and Technology (FCT) scientific program for the National Network of Electron Microscopy (RNME) $\mathrm{EDE} / 1511 / \mathrm{RME} / 2005$. 